\title{
An application of the LePSA methodology for health education in leprosy
}

\author{
J L LENNON* \& D W COOMBS †† \\ *Department $\dagger$ Health Behavior, School of Public Health, University \\ of Alabama at Birmingham, Alabama, USA
}

Accepted for publication 7 October 1991

\begin{abstract}
Summary This paper describes how the innovative LePSA technique can be used by community health workers to appropriately educate and increase compliance among leprosy patients. A lesson plan illustrating the interactive nature of the technique in a hypothetical Third World community is presented. The lesson plan, using MDT default, shows how the technique can elicit individual participation in a group setting and serve as both an educational and a behaviour change tool.
\end{abstract}

\section{Introduction}

In leprosy, early diagnosis and patient compliance with drug therapy are critical for control of the disease. ${ }^{1}$ With respect to compliance, there is a large literature on the problems encountered with leprosy and other chronic diseases. ${ }^{1-6}$ In addition, efforts have been made by health educators as well as other social scientists to reduce noncompliance. ${ }^{7}$ McDougall \& Georgiev state, however, that although there are good educational materials for health workers, little exists for patients; they present an outline of basic information needed by leprosy patients to improve compliance with drug regimens. ${ }^{7}$

We propose here the application of a new interactive health education/training method (called 'LePSA') to enable community health workers (CHW's) to improve knowledge and compliance among leprosy patients.

\section{The LePSA Method}

Leprosy control should ideally be accomplished through small groups in the community, including family/household groups, as well as through individual counselling. There are many techniques for accomplishing health education in groups but the best are 'interactive' involving the client or patient and eliciting his/her attitudes and involvement $\ddagger$ Correspondence and reprints. 
throughout the educational process. A very effective technique of this type is the LePSA method. LePSA is a culturally sensitive, community-based methodology easily learned and used by health workers. As formulated by Dr Roy Shaffer in Kenya, LePSA stands for:

Le, Learner-centred; P, Problem-posing; S, Self-discovery; A, Action-oriented. ${ }^{8}$

Learner-centred refers to a focus on the beliefs, needs and concerns of the participants. Empirically, this is facilitated by group formation of 5-12 participants in a circle. The community health worker or facilitator does not sit above or away from others and does not appear to control the session. Everyone has eye contact. People are made to feel at home among friends after appropriate introductions and small talk. Each participant is tactfully but directly requested to participate. The CHW allows a great deal of latitude and time for expression of each participant's views. Structure and control is maintained primarily by prior agreement to discuss a single problem.

The problem-posing phase emphasizes the presentation of a single problem as facilitated by the $\mathrm{CHW} .{ }^{8}$ The problem may be presented in a variety of ways, i.e. a story, a picture or most effectively through role play with the assistance of the participants. It is important that the $\mathrm{CHW}$ does not suggest a solution to the problem. This problem-posing role play is called the 'starter'. After the starter is completed, the CHW asks 3 questions:

What specific things or people did you see in the starter?

What was happening? (Was the specific, posed problem recognized as a problem by those gathered?)

Does this problem happen in our place or situation? ${ }^{8}$

In addition, the $\mathrm{CHW}$ or facilitator may probe for specific effects of the problem on the participants and their community. This discussion is ended by reaching a consensus on the nature of the problem as it occurs locally.

The discussion then enters the self-discovery phase, whereby, through dialogue, the participants discover and verbalize root causes. Shaffer says 'such a discovery lesson should result in the learner exclaiming "AHA!!!", and having a positive "aha-attitude" towards the posed problem.' That is, each learner contributes sufficiently to the dialogue so as to feel like an active, valuable group member. During the self-discovery phase the following questions guide discussion:

Why does it happen-what are the causes of this problem?

What are the side-effects or complications?

What are the possible solutions which we ourselves can carry out in the community? ${ }^{8}$

The self-discovery stage is designed to clarify the participant's knowledge as well as stimulate feelings of competence through active involvement in defining the problem and discovering solutions or answers. This leads to the action phase. At this point there is a consensus on a given solution(s) or strategy(ies) and specific means are devised for implementation with contributions from each participant. ${ }^{8}$

The LePSA method is highly flexible and can be used to communicate specific information of virtually any kind through lesson plans or training modules. In addition, it can be integrated with other health education techniques like those emphasizing audiovisual tools or social marketing. With respect to leprosy, modules can be developed for topical areas such as leprosy identification, sociocultural aspects of stigma, side-effects 
such as darkening of the skin that may occur with some drugs, such as clofazimine, leprosy patient defaulting and deformity prevention. The choice of a specific problem to be covered may be left to the participants or suggested by a health worker. Other important topics are not ignored when they spontaneously arise, i.e. the relationship of leprosy to other health problems, sanitation, and hygiene practices. The $\mathrm{CHW}$, however, is trained to redirect the group back to the original problem. ${ }^{8}$ Below is a summary of how the LePSA technique might be applied.

\section{A LEPSA LESSON PLAN FOR LEPROSY HEALTH EDUCATION}

\section{Group}

The group in this theoretical example is made up of residents from an area of high leprosy concentration. Participants may include both leprosy patients, family and nonleprosy neighbours. Ideally the group size should be no more than twelve.

\section{Subject}

The problem of multidrug therapy (MDT) defaulters

\section{Objectives}

1 To promote early diagnosis and regular use of drug therapy among leprosy patients.

2 To demonstrate the dangers of discontinuing antileprosy medication.

\section{Materials}

A couple of 'actresses' (chosen from the group), with 2 towels or some clothes used for a simulated clothes washing.

\section{Method-Role Play}

Scene One: 2 women, both afflicted with leprosy, are washing clothes together. The first woman says, 'I have not seen you in the clinic for a while to receive your medicine along with us.' The second woman replies, 'Oh, I stopped taking the medicine when it caused a lot of pain in my arms. Maybe it's just my fate. I'm not sure what to do.'

Scene Two: 6 months later the 2 women are washing clothes again. The second woman says, 'You are looking fine.' The first woman responds, 'Thank you. I've been taking my medicine when I should even when it's hard for me. But now I am much better. How do you feel?' The second woman responds, 'Well not so good, my arm and fingers have been somewhat numb lately. I just haven't been able to take the medicine as I should.'

The role play stops.

\section{Questions}

The CHW, as facilitator, asks 'starter' and 'self-discovery' questions to initiate and maintain discussion. 


\section{Concepts/Knowledge}

The discussion should lead to the following consensus.

1 The cause of leprosy is not necessarily sin or hereditary..$^{9}$ It is caused by Mycobacterium leprae or germs. Leprosy and the associated pain and numbness can best be arrested by early diagnosis and taking the right drugs for a certain length of time. The need for adherence is emphasized. Problems with adherence, such as the following, may be discussed:

a One should continue medication if there is pain or inflammation.

b Other drugs such as analgesics or anti-inflammatories may be taken if there is pain or neuritis.

c One should go to the clinic or health post if there are any side-effects. ${ }^{10}$

2 Consensus is also reached that it is important to begin early MDT. Ways to increase feasibility of regular MDT are discussed.

3 Consensus is reached about the dangers of defaulting.

a A slower cure.

b Increased skin and nerve damage.

c Increased potential for muscle wasting. ${ }^{10}$

\section{Action point}

At this stage the participants are asked to share at least one new insight about MDT defaulting with at least one other person in the community. Those with leprosy or those related to or knowledgeable about someone with leprosy are asked to return to a new meeting to discuss how MDT participatation can be increased or facilitated. Clinical referrals or appointments are also made at this point if requested. These measures will help reduce the transmission of leprosy in the community.

\section{Evaluation (optional)}

At a specified time depending on resources and need, participants can be tested with respect to knowledge and behaviour changes. A study by Matthews in India emphasized the importance of using behavioural objectives to estimate the success of any leprosy health education programme. ${ }^{11}$

Other modules or lession plans utilize the same LePSA format. This example utilizes the case of leprosy default, but there are various reasons for defaulting and thus various potential topics for this problem. ${ }^{12,13}$

\section{Discussion}

The LePSA method has the potential for utilization with a wide range of health problems associated with leprosy. The first author has witnessed the use of the LePSA method in Kenya, where it was developed, and has used it for a variety of health problems in the Philippines. It is particularly promising for teaching leprosy control cross-culturally at the community level because of its simplicity, adaptability to activities of every-day living, ease of integration with other educational techniques and the involvement of participants 
in the learning process. Von Parjis says, 'health workers have difficulty formulating advice, instructions and explanations from the patient's or the public's point of view.... Such communication is ineffective. ${ }^{14}$ The LePSA method helps the CHW overcome this barrier because he or she communicates information by requiring the learner to discover, discuss and select locally relevant ideas about the nature of the problem as well as solutions. The method is applied at the learner's pace and takes more time than simple instruction. However, it increases the probability of real understanding and provides a framework for immediate action.

\section{Acknowledgments}

Thanks to Sue Williams and Chona Lennon for manuscript preparation and technical assistance.

\section{References}

1 Lennon JL. A review of health education in leprosy. Int J Lepr, 1988; 56: 61 1-618.

2 Marston MV. Compliance with medical regimens. A review of the literature. Nurs Res, 1970; $19: 312$.

${ }^{3}$ Haynes RB, Wayne Taylor D, Sackett DL (eds). Compliance in health care. Johns Hopkins University Press, briefing, 4, 1983.

${ }^{4}$ Hertoijs Ar. A study of some factors affecting the attendance of patients in a leprosy control scheme. Int $J$ Lepr, 1974; 42: 419-427.

5 Ellard GA. Drug compliance in the treatment of leprosy. Lepr Rev, 1981; 52: 419-427.

6 Langhorne P, Duffus P, Berkeley JS, Jesudasan K. Factors influencing attendance during the multidrug therapy of leprosy. Lepr Rev, 1986; 57: 17-30.

7 McDougall AC, Georgiev GD. Educational material for the patient with leprosy. Lepr Rev, 1989; 60: 221228.

8 Shaffer R. Community-balanced development. MAP Monograph No. 1, East Africa Series. Nairobi, Kenya: MAP International, n.d., pp. 30.

${ }^{9}$ Neville PJ. A guide to health education in leprosy. Addis Ababa, Ethiopia: ALERT 1982, pp. 19.

10 Essential Drugs: Leprosy affects more than 10 million people worldwide. WHO Drug Info, 1988; 2: $152-157$.

"Matthews CME. Application of health education model to obtain early and regular treatment of leprosy patients. Int J Lepr, 1989; 57: 844-846.

12 Bhagoliwal A, Chandra J and Mishra RS. Some observations on default among leprosy patients. Lepr India, 1979; 51: 96-102.

13 Mull JD, Wood CS, Gans LP, Mull DS. Culture and compliance a mong leprosy patients in Pakistan. Soc Sci Med, 1989; 29: 799-811.

14 Van Parjis LG. Redefining health education in leprosy: a personal view. Lepr Rev, 1990; 61: 97-111. 


\section{La méthodologie LePSA appliquée à l'éducation sur la lèpre}

\section{J L LENNON ET D W COOMBS}

Résumé Ce document décrit comment la technique innovatrice LePSA peut être utilisée par les travailleurs sociaux pour éduquer les malades et en amener le plus grand nombre à accepter. On y présente un projet pédagogique illustrant la nature interactive de la technique dans une communauté imaginaire du tiers monde. Le projet pédagogique, faisant appel à une médication mixte, montre comment cette technique peut susciter la participation de chaque individu dans un groupe et servir aussi bien pour former que pour faire changer les comportements.

\section{Una aplicación de la metodología LePSA en la educación sanitaria de la lepra}

\section{J L LENNON Y D W COOMBS}

Resumen Esta publicación resume cóma los que trabajan en la salud comunitaria pueden usar la técnica innovadora LePSA para capacitar adecuadamente y aumentar la conformidad de los pacientes con lepra. En un plan de lecciones se presenta el caracter interactivo de la técnica en una comunidad hipotética del Tercer Mundo. El plan, que utiliza MDT por def ector, demuestra cómo la técnica puede estimular la participación de individuos en un ambiente de grupo, y servir de herramienta tanto educacional como relativa al compartamiento, 